\title{
Combined effects of endurance training and dietary unsaturated fatty acids on physical performance, fat oxidation and insulin sensitivity
}

\author{
Andreas Boss ${ }^{1,2}$, Virgile Lecoultre ${ }^{1}$, Christiane Ruffieux ${ }^{3}$, Luc Tappy $^{1} *$ and Philippe Schneiter ${ }^{1}$ \\ ${ }^{1}$ Department of Physiology, University of Lausanne, Lausanne, Switzerland \\ ${ }^{2}$ Institute of Human Movement Sciences and Sport, ETH Zurich, Zurich, Switzerland \\ ${ }^{3}$ Department of Social and Preventive Medicine, Centre Hospitalier Universitaire Vaudois and University of Lausanne, Switzerland
}

(Received 30 April 2009 - Revised 18 September 2009 - Accepted 14 October 2009 - First published online 1 December 2009)

Endurance training improves exercise performance and insulin sensitivity, and these effects may be in part mediated by an enhanced fat oxidation. Since $n-3$ and $n-9$ unsaturated fatty acids may also increase fat oxidation, we hypothesised that a diet enriched in these fatty acids may enhance the effects of endurance training on exercise performance, insulin sensitivity and fat oxidation. To assess this hypothesis, sixteen normal-weight sedentary male subjects were randomly assigned to an isoenergetic diet enriched with fish and olive oils (unsaturated fatty acid group (UFA): $52 \%$ carbohydrates, $34 \%$ fat (12\% SFA, $12 \%$ MUFA, $5 \%$ PUFA), $14 \%$ protein), or a control diet (control group (CON): $62 \%$ carbohydrates, $24 \%$ fat (12\% SFA, $6 \%$ MUFA, $2 \%$ PUFA), $14 \%$ protein) and underwent a $10 \mathrm{~d}$ gradual endurance training protocol. Exercise performance was evaluated by measuring $\mathrm{VO}_{2 \max }$ and the time to exhaustion during a cycling exercise at $80 \% \mathrm{VO}_{2 \max }$; glucose homeostasis was assessed after ingestion of a test meal. Fat oxidation was assessed by indirect calorimetry at rest and during an exercise at $50 \% \mathrm{VO}_{2 \max }$. Training significantly increased time to exhaustion, but not $\mathrm{VO}_{2 \max }$, and lowered incremental insulin area under the curve after the test meal, indicating improved insulin sensitivity. Those effects were, however, of similar magnitude in UFA and CON. Fat oxidation tended to increase in UFA, but not in CON. This difference was, however, not significant. It is concluded that a diet enriched with fish- and olive oil does not substantially enhance the effects of a short-term endurance training protocol in healthy young subjects.

Unsaturated fatty acids: Insulin sensitivity: Physical performance: Fat oxidation

Since Bang et al. ${ }^{(1)}$ reported that the low incidence of type 2 diabetes mellitus and CVD in indigenous residents of Greenland was related to a high intake of long-chain $n-3$ fatty acids, health benefits of those fatty acids have been widely investigated. $n-3$ Fatty acids lower plasma and muscle TAG, have anti-inflammatory, anti-thrombotic, vasodilatory and mild hypotensive effects ${ }^{(2)}$. Mechanisms of action may involve the incorporation of $n-3$ fatty acids in plasma membranes, and/or subsequent modulations of PG and eicosanoid metabolism ${ }^{(3-5)}$. Thus, it was shown that an increased proportion of $n-3$ fatty acids in the membrane of cardiomyocytes was related to an improved heart function ${ }^{(3,4)}$. The effect of $n-3$ fatty acids on glucose homeostasis remains, however, controversial. Fish oil supplementation efficiently prevents the development of insulin resistance induced by a high-fat diet in rodents ${ }^{(6)}$, but has also been reported to worsen glucose homeostasis in type 2 diabetes $^{(7-10)}$. Since insulin resistance appears to be closely linked to altered lipid metabolism and lipotoxicity, and since $n-3$ fatty acids may promote fat oxidation ${ }^{(11)}$, it can be hypothesised that fish oil supplementation would be more efficient when combined with another intervention aimed at increasing fat oxidation.
Not only $n-3$ fatty acids, but also dietary MUFA are held to exert beneficial effects to prevent metabolic disorders. Olive oil, rich in $n-9$ unsaturated fatty acids, is an important component of the 'Mediterranean diet', which has been reported to lower cardiovascular risk. Meals or diets rich in MUFA have also been associated with a stimulation of lipid oxidation in human subjects ${ }^{(12,13)}$.

Endurance training increases whole-body insulin sensitivity, improves glucose tolerance, and contributes to a loss of body fat mass in overweight, insulin-resistant individuals ${ }^{(14-16)}$. Furthermore, endurance training enhances fat oxidation ${ }^{(17)}$, and this effect may be instrumental in increasing exercise performance and improving glucose homeostasis.

Since endurance training and diets high in unsaturated fatty acids share several beneficial effects on metabolic and cardiovascular health, and since both may involve an improved fat oxidative capacity, we hypothesised that their combination may have synergic or additive effects. Specifically, we expected that physical performance, fat oxidation and insulin sensitivity would increase after short-term training and that this increase would be enhanced in subjects receiving a diet in which part of the carbohydrates were replaced by $n-3$ and $n-9$ unsaturated fatty acids.

Abbreviations: CON, control group; HR, heart rate; IncAUC, incremental area under the curve; UFA, unsaturated fatty acids group.

* Corresponding author: Professor Luc Tappy, fax +412169255 95, email Luc.Tappy@unil.ch 
Table 1. Anthropometric data*

(Mean values and standard deviations)

\begin{tabular}{|c|c|c|c|c|c|c|c|c|c|c|c|}
\hline & \multicolumn{4}{|c|}{ UFA $(n 8)$} & \multicolumn{4}{|c|}{ CON $(n 8)$} & & & \\
\hline & \multicolumn{2}{|c|}{ Pre } & \multicolumn{2}{|c|}{ Post } & \multicolumn{2}{|c|}{ Pre } & \multicolumn{2}{|c|}{ Post } & \multicolumn{3}{|c|}{$P$} \\
\hline & Mean & SD & Mean & SD & Mean & SD & Mean & SD & Group & Time & Group $\times$ time \\
\hline Age (years) & $25 \cdot 0$ & 4.3 & & & $22 \cdot 5$ & $2 \cdot 1$ & & & & & \\
\hline Height (cm) & $175 \cdot 7$ & 5.0 & & & $177 \cdot 8$ & 3.4 & & & & & \\
\hline Weight (kg) & $70 \cdot 2$ & $9 \cdot 3$ & $70 \cdot 4$ & 9.6 & 74.4 & $4 \cdot 3$ & 74.0 & $4 \cdot 2$ & 0.25 & 0.12 & 0.11 \\
\hline$\%$ FFM & 83 & 6 & 84 & 7 & 80 & 8 & 81 & 8 & 0.51 & 0.57 & 0.35 \\
\hline$\%$ FAT & 17 & 6 & 16 & 7 & 20 & 8 & 19 & 8 & 0.51 & 0.69 & 0.27 \\
\hline BMI $\left(\mathrm{kg} / \mathrm{m}^{2}\right)$ & $22 \cdot 7$ & 2.5 & & & 23.5 & 0.9 & & & & & \\
\hline $\mathrm{SBP}(\mathrm{mmHg})$ & 129 & 13 & & & 125 & 9 & & & & & \\
\hline DBP $(\mathrm{mmHg})$ & 76 & 8 & & & 75 & 10 & & & & & \\
\hline
\end{tabular}

UFA, unsaturated fatty acids group; CON, control group; FFM, fat-free mass; FAT, fat mass; SBP, systolic blood pressure; DBP, diastolic blood pressure.

* Weight was the average of the two testing days, measured in the fasting state in the morning. Body composition was assessed by bioimpedance techniques.

\section{Subjects and methods}

\section{Subjects}

The study participants were sixteen young sedentary men. A physical examination and a brief medical history revealed that the participants were in good health. They had no family history of diabetes and did not take any drugs. They were non-smokers and did not drink alcohol on a regular basis. Subject characteristics are displayed in Table 1. The participants were included if they self-reported a low habitual physical activity ( $<1 \mathrm{~h}$ per week) for at least the past 1 year and if their $\mathrm{VO}_{2 \max }$, assessed by an incremental exercise test, was less than $50 \mathrm{ml} / \mathrm{kg}$ per min.

\section{Study design}

The study design is presented in Fig. 1. Participants were randomly assigned to receive either a diet in which $10 \%$ of dietary carbohydrates was substituted with $n-3$ fatty acids (Omega 3 Gisand; Gisand ${ }^{\circledR}$, Bern, Switzerland; six capsules per d; two per meal, providing a total daily dose of $1.1 \mathrm{~g}$

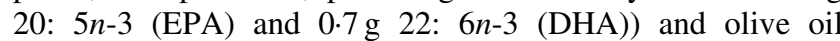
(unsaturated fatty acid group; UFA) or a balanced control diet (control group; $\mathrm{CON}$ ). Both diets were isoenergetic, and total energy intake was calculated as predicted by the RMR (using the equation of Owen ${ }^{(18)}$ ) times 1.4 to account for a low usual physical activity. Complete description of the diets is given in Table 2. After inclusion, all subjects consumed the assigned diet for 4 weeks. During the initial 2 weeks, the diet was followed according to the prescription made by a registered dietitian. During $3 \mathrm{~d}$ before the preliminary metabolic tests and during the last 2 weeks, all the food was prepared at the Department of Physiology and was provided to the participants.

At the end of week -1 , glucose and lipid homeostasis and substrate oxidation were assessed by indirect calorimetry after the ingestion of a test meal; this test was immediately followed by a measurement of $\mathrm{VO}_{2 \max }$. On the following day, an exercise test (cycling on an ergometric bicycle at $50 \% \mathrm{VO}_{2 \max }$ ) was performed, and substrate oxidation was monitored with indirect calorimetry. A lipid load of olive oil labelled with $\left[{ }^{13} \mathrm{C}_{3}\right]$ triolein was administered orally and breath ${ }^{13} \mathrm{CO}_{2}$ was monitored to calculate exogenous lipid oxidation. Immediately after this exercise test, endurance capacity was measured. This test consisted of cycling at a power output corresponding to the subjects' $80 \% \mathrm{VO}_{2 \max }$ until exhaustion.

Endurance training started at day 1 of the third week and consisted of eight sessions of indoor cycling with the exercise intensity increasing over the $10 \mathrm{~d}$ period (Fig. 1). A gradual training protocol was chosen based on the hypothesis that, during the training process, morphological and metabolic adaptations are triggered by an exercise-induced cellular energy deficit, leading to activation of AMP-activated protein kinase ${ }^{(19)}$, and on the observation that the threshold for considerable AMP-activated protein kinase activation seems to move toward higher exercise intensities over time ${ }^{(20)}$. Since fat oxidation was one major endpoint in the present study, we hypothesised that an optimal stimulus aimed at increasing fat oxidation would be in the range of intensities eliciting maximal fat oxidation rates, reported to be between 45 and $64 \% \mathrm{VO}_{2 \max }{ }^{(21,22)}$.

Dietary intakes were adapted on training days to account for the extra energy expended during training sessions. The test meal and $\mathrm{VO}_{2 \max }$ measurements were repeated on

\begin{tabular}{l} 
Controlled diet \\
Provided food, isoenergetic diet \\
\begin{tabular}{|l|l|l|l|l|l|l|l|l|l|l|}
\hline \multicolumn{10}{|c|}{ Supervised training } \\
\hline$\% \mathrm{VO}_{2 \max }$ & 50 & 50 & 55 & 55 & 60 & - & - & 60 & 65 & 50 \\
\hline Duration (min) & 30 & 45 & 30 & 45 & 30 & - & - & 45 & 30 & 45 \\
\hline W-2 W -1 & D1 D2 D3 D4 D5 D6 D7 D8 & D9 D10 D11 D12 \\
\hline
\end{tabular} \\
\hline
\end{tabular}

Fig. 1. Experimental design. Diet was controlled during the first 2 weeks, week $-2(\mathrm{~W}-2)$ and week $-1(\mathrm{~W}-1)$. All the food was provided to the volunteers during the $3 \mathrm{~d}$ preceding the preliminary tests and from the beginning of the training period (day (D) 1) until D 11. Supervised bicycle ergometer training was performed in the morning in the fed state. Intensity increased steadily from 50 to $65 \% \mathrm{VO}_{2 \max }$. The sessions lasted either 30 or $45 \mathrm{~min}$. Preliminary tests (test meal and $\mathrm{VO}_{2 \max }$; exercise- and endurance capacity test) took place on two consecutive days during $W-1$ and were repeated after completion of the training programme on D 11 and $D 12$. 
Table 2. Energy content and composition of the provided diets (Mean values and standard deviations)

\begin{tabular}{|c|c|c|c|c|}
\hline & \multicolumn{2}{|c|}{ UFA $(n 8)$} & \multicolumn{2}{|c|}{$\operatorname{CON}(n 8)$} \\
\hline & Mean & SD & Mean & SD \\
\hline El $(\mathrm{MJ} / \mathrm{d})$ & $10 \cdot 13$ & 0.50 & $10 \cdot 32$ & 0.19 \\
\hline Carbohydrate (\% El) & 52 & & 62 & \\
\hline Fat $(\%$ EI) & 34 & & 24 & \\
\hline Protein (\% El) & 14 & & 14 & \\
\hline SFA (\% EI) & 12 & & 12 & \\
\hline MUFA (\% EI) & 12 & & 6 & \\
\hline PUFA (\% EI) & 5 & & 2 & \\
\hline Supplemented EPA and DHA (\% EI) & 0.7 & & - & \\
\hline
\end{tabular}

UFA, unsaturated fatty acids group; CON, control group; EI, energy intake.

day 11 and the exercise and endurance capacity tests on day 12 after the beginning of training.

The present study was conducted according to the guidelines laid down in the Declaration of Helsinki and all procedures involving human subjects were approved by the ethics committee of Lausanne University School of Medicine. Written informed consent was obtained from all subjects.

\section{Experimental procedures}

Test meal. The purpose of this test meal was to determine how diet and training modulated glucose tolerance and insulin sensitivity on one hand, and lipid oxidation on the other hand. A test meal with a high carbohydrate content, identical in both groups, was selected. The subjects reported at 07.00 hours to the metabolic unit of the Lausanne University Hospital after an overnight fast. On arrival, the subjects were asked to void, and their body composition was estimated by bioimpedance technique (Imp DF50; ImpediMed, Eight Mile Plains, Australia). An indwelling catheter was inserted into an antecubital vein of the wrist for blood sampling. After a $30 \mathrm{~min}$ rest period, resting energy metabolism was measured by open-circuit indirect calorimetry (Deltatrac II; Datex Instruments, Helsinki, Finland). Net substrate oxidation rates were calculated from respiratory gas exchanges and urinary $\mathrm{N}$ excretion using the equations of Livesey \& Elia ${ }^{(23)}$. After basal recordings were obtained during $30 \mathrm{~min}$ (from $\mathrm{T}-45$ to $\mathrm{T}-15$ ), the ventilatory canopy was removed and subjects consumed within $15 \mathrm{~min}$ a standardised mixed meal corresponding to $29 \%$ of their daily energy requirements, containing $69 \%$ of energy as carbohydrates, $13 \%$ as protein and $18 \%$ as fat. At T0, indirect calorimetry was resumed and continued for the next $240 \mathrm{~min}$. Venous blood samples were collected at $\mathrm{T}-15$ (baseline) and then from $\mathrm{T}+30$ to $\mathrm{T}+240$ at $30 \mathrm{~min}$ intervals. Blood samples were immediately centrifuged at $4^{\circ} \mathrm{C}$, plasma was sampled and stored at $-20^{\circ} \mathrm{C}$ until analysis.

$V O_{2 \max }$. $\mathrm{VO}_{2 \max }$ was assessed during an incremental exercise test performed on a cycle ergometer. Respiratory gas exchanges were measured breath-by-breath using an indirect calorimetry cart (Vmax Spectra V29c; SensorMedics, Yorba Linda, CA, USA). Data were averaged at $30 \mathrm{~s}$ intervals. The exercise was started at a power output of $50 \mathrm{~W}$, which was increased by $25 \mathrm{~W}$ every $2 \mathrm{~min}$. Heart rate (HR) was continuously monitored. Ratings of perceived exertion were assessed with the Borg scale (with levels 0-10) and were recorded at the end of every workload. The test ended when the subjects voluntarily stopped or when they could not maintain the exercise cadence of $70 \mathrm{rpm}$ any more. Criteria for the determination of $\mathrm{VO}_{2 \max }$ were: plateau in $\mathrm{O}_{2}$ consumption with increasing work rate $\left(\Delta \mathrm{O}_{2}\right.$ $<150 \mathrm{ml} / \mathrm{min}$ ). Secondary criteria were: RER $>1.10$ and ratings of perceived exertion $>8$.

Exercise test. Subjects reported to the metabolic unit at 07.00 hours after an overnight fast. During the first $180 \mathrm{~min}$, subjects rested in a supine position. At four time points $-\mathrm{T} 0, \mathrm{~T}+60, \mathrm{~T}+120$ and $\mathrm{T}+180$ - the subjects ingested $10.5 \mathrm{~g}$ olive oil containing $1 \%$ of labelled $\left[1,1,1-{ }^{13} \mathrm{C}_{3}\right]$ triolein $(99 \%)$ (Cambridge Isotope Laboratories, Andover, MA, USA). Breath samples were collected in $10 \mathrm{ml}$ glass containers at $\mathrm{T}-30$ and $\mathrm{T} 0$ to determine basal ${ }^{13} \mathrm{CO}_{2}$ abundance by $\mathrm{MS}$ and at $\mathrm{T}+120, \mathrm{~T}+150$ and $\mathrm{T}+180$ to estimate exogenous fat oxidation. Thereafter the exercise bout started. At time $\mathrm{T}+220$, the subjects warmed up at $60 \mathrm{~W}$ for $5 \mathrm{~min}$, then they cycled during $45 \mathrm{~min}$ at a power output corresponding to approximately $50 \% \mathrm{VO}_{2 \max }$ (i.e. the workload which elicited $50 \%$ of $\mathrm{VO}_{2 \max }$ during the $\mathrm{VO}_{2 \max }$ test.). Indirect calorimetry was performed during the last $30 \mathrm{~min}$. Blood and breath samples were collected at $\mathrm{T}+240, \mathrm{~T}+255$ and $\mathrm{T}+270$. At the same time points, ratings of perceived exertion were assessed. After the training period, the tests were performed at the same absolute power outputs.

Endurance capacity test. At the end of the exercise test, workload was increased to elicit $80 \%$ of the participants' $\mathrm{VO}_{2 \max }$. The subjects were asked to maintain the pedalling frequency at $70 \mathrm{rpm}$ as long as possible. Time to exhaustion was assessed as a measure of endurance capacity. HR was continuously recorded and ratings of perceived exertion were recorded at $2 \mathrm{~min}$ intervals. The test was stopped upon voluntary cessation of exercise or when the pedalling frequency could not be maintained any more. Water was provided ad libitum.

\section{Training}

Each subject engaged in a supervised endurance training programme on a bicycle ergometer (Ergoline, Bitz, Germany) for $8 \mathrm{~d}$ (day 1 to day 5 and day 8 to day 10). Training was performed in the morning after breakfast. Exercise intensity increased gradually from $50 \% \mathrm{VO}_{2 \max }$ to $65 \% \mathrm{VO}_{2 \max }$ at day 9. Exercise duration was 30 and $45 \mathrm{~min}$ on alternate days (Fig. 1). At day 10 exercise intensity was reduced to $50 \%$. Day 6 and day 7 were resting days.

\section{Analytical procedures}

Colorimetric methods were used to assess plasma concentrations of NEFA (kit from Wako Chemicals, Freiburg, Germany) and TAG (kit from Biomérieux Vitek, Lyon, France). Commercial RIA kits were used for the determination of plasma insulin and glucagon (LINCO Research, St Charles, MO, USA). Concentrations of lactate and $\beta$-hydroxybutyric acid were measured enzymically using kits from Boehringer (Boehringer, Mannheim, Germany). 
Table 3. $\mathrm{VO}_{2 \max }$

(Mean values and standard deviations)

\begin{tabular}{|c|c|c|c|c|c|c|c|c|c|c|c|}
\hline & \multicolumn{4}{|c|}{ UFA $(n 8)$} & \multicolumn{4}{|c|}{$\mathrm{CON}(n 8)$} & & & \\
\hline & \multicolumn{2}{|c|}{ Pre } & \multicolumn{2}{|c|}{ Post } & \multicolumn{2}{|c|}{ Pre } & \multicolumn{2}{|c|}{ Post } & \multicolumn{3}{|c|}{$P$} \\
\hline & Mean & SD & Mean & SD & Mean & SD & Mean & SD & Group & Time & Group $\times$ time \\
\hline $\mathrm{VO}_{2 \max }(\mathrm{ml} / \mathrm{kg}$ per min) & $41 \cdot 1$ & 4.8 & 41.4 & $4 \cdot 8$ & $40 \cdot 3$ & $4 \cdot 3$ & $41 \cdot 7$ & $4 \cdot 3$ & 0.74 & 0.27 & 0.55 \\
\hline $\mathrm{VO}_{2 \max }($ litres/min $)$ & $2 \cdot 85$ & 0.3 & 2.90 & 0.31 & 3.01 & 0.33 & 3.09 & 0.39 & 0.38 & 0.39 & 0.79 \\
\hline $\mathrm{W}_{\max }(\mathrm{W})$ & 205 & 36 & 222 & 35 & 224 & 124 & 238 & 33 & 0.27 & 0.01 & $0 \cdot 70$ \\
\hline
\end{tabular}

UFA, unsaturated fatty acids group; CON, control group; $\mathrm{W}_{\max }$, maximum workload.

Plasma glucose concentrations were measured by the glucose oxidase method (Glucose Analyser II; Beckman Instruments, Fullerton, CA, USA). Enrichment of ${ }^{13} \mathrm{C}$ in expired breath samples was determined by isotope ratio MS (Sercon, Crewe, Cheshire, UK). GC-MS (model 5979; HewlettPackard, Palo Alto, CA, USA) was used for the determination of DHA:palmitate and DHA:linoleate ratios in plasma lipids as markers of compliance to $n-3$ fatty acid consumption ${ }^{(24)}$.

\section{Statistical analysis}

The effect of group, time (training) and their interaction on variables of interest was assessed by using linear regression with random coefficients. To determine differences between the two groups for the baseline anthropometric data as well as for exercise intensity during the exercise test and the endurance capacity test, $t$ tests for unpaired data were used. Correlations were assessed by the non-parametric Spearman test. Level of significance was set at $\alpha=0.05$. All the tests were performed with STATA software (version 9.1; StataCorp LP, College Station, TX, USA).

\section{Results}

\section{Body composition}

All participants complied with the supervised training protocol successfully. Their body weight and body composition were not different at the beginning and the end of the training period (Table 1).

\section{$\mathrm{VO}_{2 \max }$ and endurance capacity}

$\mathrm{VO}_{2 \max }$ results are shown in Table 3 . Briefly, training did not significantly increase $\mathrm{VO}_{2 \max }$, neither expressed in absolute value nor normalised for body mass. In contrast, the maximal workload achieved during the incremental test increased by 8 and $6 \%$ in UFA and CON, respectively. No significant effect of group or significant group $\times$ time interaction was observed.

The evolution of endurance capacity is shown in Fig. 2. The test was performed at similar workloads, 159 (SD 30) $\mathrm{W}$ in UFA and 171 (SD 32) W in CON $(P=0.48)$ and increased by 129 and $116 \%$ in UFA and CON, respectively $(P<0.001$ for time).

\section{Test meal}

Detailed results of fasting substrate oxidation and of plasma hormone and substrate concentration are displayed in Table 4. In UFA fat oxidation was 0.53 (SD 0.31 ) $\mathrm{mg} / \mathrm{kg}$ per min before, and $0.70(\mathrm{SD} 0.39) \mathrm{mg} / \mathrm{kg}$ per min after training. In CON fat oxidation was $0.62(\mathrm{SD} 0.20) \mathrm{mg} / \mathrm{kg}$ per $\mathrm{min}$ and $0.64(\mathrm{SD} 0.21) \mathrm{mg} / \mathrm{kg}$ per $\mathrm{min}$ for pre- and post-training, respectively $(P=0.57$ for group; $P=0.75$ for time; $P=0.28$ for group $\times$ time). Basal energy expenditure was slightly decreased after training at a borderline significant level $(P=0.07$ for time). Basal TAG concentrations were lower in UFA $(P=0.02$ for group) and were reduced after training $(P=0.001)$; this decrease was similar in CON $(P=0.57$ for group $\times$ time). Plasma insulin tended to decrease only in UFA $(P=0.09$ for group $\times$ time $)$.

Mean substrate oxidation during the $4 \mathrm{~h}$ following ingestion of the mixed meal and incremental area under the curve (incAUC) for blood metabolites and insulin are displayed in Table 5. Average fat oxidation decreased in response to the test meal. It was $0.28(\mathrm{SD} 0.21) \mathrm{mg} / \mathrm{kg}$ per min before, and $0.38(\mathrm{SD} 0.20) \mathrm{mg} / \mathrm{kg}$ per min after training in UFA; in $\mathrm{CON}$ it was $0.32(\mathrm{SD} 0 \cdot 10) \mathrm{mg} / \mathrm{kg}$ per $\mathrm{min}$ and 0.34 $(\mathrm{SD} 0 \cdot 15) \mathrm{mg} / \mathrm{kg}$ per min for pre- and post-training, respectively $(P=0.61$ for group, $P=0.75$ for time and $P=0.36$ for group $\times$ time). Insulin incAUC decreased by a similar amount in UFA and $\operatorname{CON}(P=0.01$ for time; $P=0.57$ for group $\times$ time).

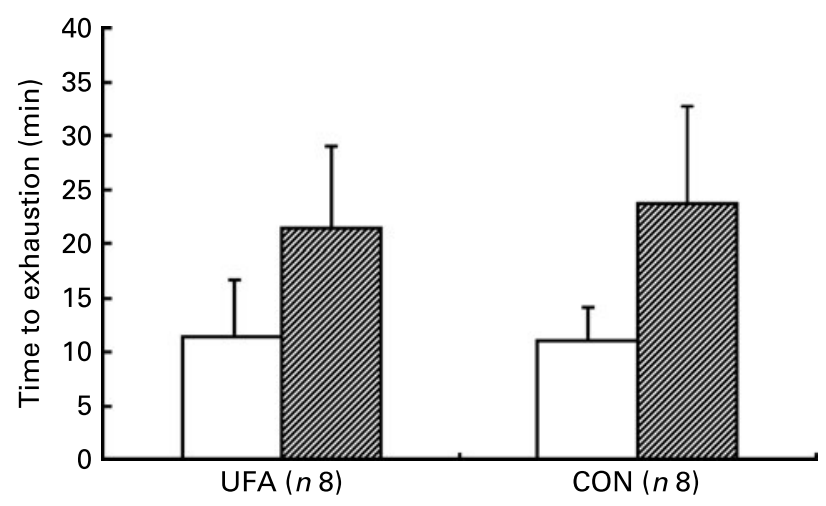

Fig. 2. Endurance capacity test. Values are means, with standard deviations represented by vertical bars. Time to exhaustion at approximately $80 \%$ $\mathrm{VO}_{2 \max }$ increased significantly from pre-training $(\square)$ to post-training $(\square)$ in the unsaturated fatty acids group (UFA) and control group (CON) $(P=0.93$ for group, $P<0.001$ for time and $P=0.56$ for group $\times$ time). 
Table 4. Test meal: indirect calorimetry and plasma parameters during basal condition (Mean values and standard deviations)

\begin{tabular}{|c|c|c|c|c|c|c|c|c|c|c|c|}
\hline & \multicolumn{4}{|c|}{ UFA $(n 8)$} & \multicolumn{4}{|c|}{ CON (n 8) } & & & \\
\hline & \multicolumn{2}{|c|}{ Pre } & \multicolumn{2}{|c|}{ Post } & \multicolumn{2}{|c|}{ Pre } & \multicolumn{2}{|c|}{ Post } & \multicolumn{3}{|c|}{$P$} \\
\hline & Mean & SD & Mean & SD & Mean & SD & Mean & SD & Group & Time & Group $\times$ time \\
\hline RER & 0.87 & 0.05 & 0.83 & 0.06 & 0.85 & 0.04 & 0.84 & 0.04 & 0.38 & 0.66 & 0.29 \\
\hline Fat oxidation (mg/kg per min) & 0.53 & 0.31 & 0.70 & 0.39 & 0.62 & 0.20 & 0.64 & 0.21 & 0.57 & 0.75 & 0.28 \\
\hline $\mathrm{CHO}$ oxidation (mg/kg per min) & 1.77 & 0.59 & $1 \cdot 28$ & 0.64 & 1.63 & 0.62 & 1.41 & 0.47 & 0.63 & 0.38 & 0.44 \\
\hline Energy expenditure $(\mathrm{kJ} / \mathrm{min})$ & $4 \cdot 27$ & 0.44 & 4.24 & 0.53 & 4.48 & 0.33 & 4.35 & 0.28 & 0.32 & 0.07 & 0.36 \\
\hline Insulin $(\mu \mathrm{U} / \mathrm{ml})$ & $8 \cdot 3$ & 3.0 & $6 \cdot 5$ & $2 \cdot 4$ & $7 \cdot 4$ & 1.5 & $7 \cdot 3$ & $2 \cdot 8$ & 0.46 & 0.89 & 0.09 \\
\hline Glucose $(\mathrm{mmol} / \mathrm{l})$ & 4.5 & 0.5 & 4.6 & 0.7 & 4.6 & 0.4 & 4.7 & 0.4 & 0.85 & 0.16 & 0.58 \\
\hline Lactate $(\mathrm{mmol} / \mathrm{l})$ & 0.9 & 0.1 & 0.8 & 0.3 & $1 \cdot 1$ & 0.4 & 0.9 & 0.2 & 0.21 & 0.02 & 0.57 \\
\hline $\mathrm{TAG}(\mathrm{mmol} / \mathrm{l})$ & 0.68 & 0.21 & 0.52 & 0.19 & 1.02 & 0.38 & 0.81 & 0.31 & 0.02 & 0.001 & 0.57 \\
\hline NEFA (mmol/l) & 0.327 & 0.140 & 0.355 & 0.146 & 0.486 & 0.087 & 0.428 & 0.138 & 0.01 & 0.33 & 0.31 \\
\hline
\end{tabular}

UFA, unsaturated fatty acids group; $\mathrm{CON}$, control group; $\mathrm{CHO}$, carbohydrate.

\section{Exercise test}

Detailed results of the exercise are displayed in Table 6. Due to a technical problem with the bicycle ergometer, the results of one subject in CON could not be included.

HR during exercise decreased significantly $(P=0.04$ for time) by 18 (SD 11) beats per min in UFA and by 7 (SD 5) bears per min in CON, this decrease being significantly greater in UFA $(P=0.01$ for group $\times$ time $)$. Fat oxidation tended to increase from 19 (SD 10) \% before to 29 (SD 7) \% of total energy expenditure after training in UFA, while it remained constant at $28 \%$ (SD 13) \% before and $29 \%$ (SD 13) \% after training in CON. There was, however, no significant difference between the two groups. Mean lactate during exercise decreased by $43 \%$ in UFA and by $23 \%$ in CON. The relative change in fat oxidation was neither associated with the relative increase in time to exhaustion $(\rho=0.17 ; P=0.54)$ nor with the change of maximal workload assessed during the $\mathrm{VO}_{2 \max }$ test $(\rho=-0 \cdot 26$; $P=0.36)$ nor with the decrease of insulin incAUC during the test meal $(\rho=-0 \cdot 11 ; P=0 \cdot 69)$.

Fig. 3 displays ${ }^{13} \mathrm{C}$ atom percent excess after ingestion of the labelled lipids at rest and during exercise. No significant effect of training, diet and their interaction was observed on ${ }^{13} \mathrm{C}$ atom percent excess.

\section{Compliance}

Compliance to diet and adherence to the provided fish oil capsules was verified by assessing the plasma DHA:palmitate and DHA:linoleate ratios in a fasting blood sample at the end of the study. DHA:palmitate was 0.13 (SD 0.01) in UFA $v .0 .06(\mathrm{SD} 0.02)$ in $\mathrm{CON}(P<0.001)$. DHA:linoleate was $0.24(\mathrm{SD} 0.04)$ and $0.12(\mathrm{SD} 0.03)$ in UFA and CON, respectively $(P<0 \cdot 001)$.

\section{Discussion}

Endurance training increases muscle fat oxidation capacity and, to a lesser extent, muscle mass. These changes in turn allow for an improved exercise performance, i.e. muscle strength and endurance. Since dietary $n-3$ and $n-9$ fatty acids are also known to enhance fat oxidation, we had hypothesised that those fatty acids would potentiate the effects of training on both fat oxidation and performance. The hypothesis of a synergistic effect of training and unsaturated fatty acids can be supported at the molecular level, by the observations that training-induced changes in muscle lipid oxidative metabolism involve the activation of the transcription factors $\operatorname{PPAR}^{(25,26)}$ or their target genes ${ }^{(27)}$ and by the fact that unsaturated fatty

Table 5. Test meal: average substrate oxidation and incremental area under the curve (incAUC) of blood parameters after mixed meal (Mean values and standard deviations)

\begin{tabular}{|c|c|c|c|c|c|c|c|c|c|c|c|}
\hline & \multicolumn{4}{|c|}{ UFA $(n 8)$} & \multicolumn{4}{|c|}{ CON (n 8) } & & & \\
\hline & \multicolumn{2}{|c|}{ Pre } & \multicolumn{2}{|c|}{ Post } & \multicolumn{2}{|c|}{ Pre } & \multicolumn{2}{|c|}{ Post } & \multicolumn{3}{|c|}{$P$} \\
\hline & Mean & SD & Mean & SD & Mean & SD & Mean & SD & Group & Time & Group $\times$ time \\
\hline RER & 0.93 & 0.04 & 0.91 & 0.03 & 0.92 & 0.02 & 0.91 & 0.02 & 0.53 & 0.62 & 0.34 \\
\hline Fat oxidation (mg/kg per min) & 0.28 & 0.21 & 0.38 & 0.20 & 0.32 & $0 \cdot 10$ & 0.34 & $0 \cdot 15$ & 0.61 & 0.75 & 0.36 \\
\hline $\mathrm{CHO}$ oxidation (mg/kg per min) & 3.06 & 0.58 & $2 \cdot 76$ & 0.44 & 3.04 & 0.45 & $2 \cdot 83$ & 0.27 & 0.93 & 0.27 & 0.73 \\
\hline Energy expenditure (kJ/min) & 4.99 & 0.57 & 4.97 & 0.61 & $5 \cdot 26$ & 0.54 & $5 \cdot 11$ & $0 \cdot 31$ & 0.30 & 0.16 & 0.38 \\
\hline Insulin $_{\text {incAUc }}(\mu \mathrm{U} / \mathrm{ml} \times \min )$ & $62 \cdot 6$ & $26 \cdot 0$ & $45 \cdot 8$ & $23 \cdot 0$ & $61 \cdot 7$ & $26 \cdot 6$ & $48 \cdot 8$ & $20 \cdot 3$ & 0.94 & 0.01 & 0.57 \\
\hline Glucose $_{\text {incAUc }}(\mathrm{mmol} / \mathrm{l} \times \mathrm{min})$ & $2 \cdot 2$ & 0.7 & $2 \cdot 2$ & 0.5 & $2 \cdot 2$ & 0.5 & $2 \cdot 0$ & 0.3 & 0.88 & 0.51 & 0.80 \\
\hline Lactate $_{\text {incAuc }}(\mathrm{mmol} / \mathrm{I} \times \mathrm{min})$ & 0.6 & 0.2 & 0.6 & 0.2 & 0.7 & 0.2 & 0.8 & 0.1 & 0.31 & 0.33 & 0.58 \\
\hline $\mathrm{TAG}_{\text {incAUc }}(\mathrm{mmol} / \mathrm{l} \times \mathrm{min})$ & 0.2 & 0.2 & 0.2 & $0 \cdot 1$ & 0.3 & 0.2 & 0.2 & 0.2 & 0.75 & 0.59 & 0.90 \\
\hline $\operatorname{NEFA}_{\text {incAUc }}(\mathrm{mmol} / \mathrm{l} \times \mathrm{min})$ & -0.163 & 0.099 & - & 0.083 & -0.254 & 0.077 & -0.205 & 0.075 & 0.03 & $0 \cdot 21$ & 0.33 \\
\hline
\end{tabular}

UFA, unsaturated fatty acids group; CON, control group; $\mathrm{CHO}$, carbohydrate. 
Table 6. Exercise at $50 \% \mathrm{VO}_{2 \max }$

(Mean values and standard deviations)

\begin{tabular}{|c|c|c|c|c|c|c|c|c|c|c|c|}
\hline & \multicolumn{4}{|c|}{ UFA $(n 8)$} & \multicolumn{4}{|c|}{$\operatorname{CON}(n 7)$} & & & \\
\hline & \multicolumn{2}{|c|}{ Pre } & \multicolumn{2}{|c|}{ Post } & \multicolumn{2}{|c|}{ Pre } & \multicolumn{2}{|c|}{ Post } & \multicolumn{3}{|c|}{$P$} \\
\hline & Mean & SD & Mean & SD & Mean & SD & Mean & SD & Group & Time & Group $\times$ time \\
\hline Workload (W) & 89 & 17 & 89 & 17 & 94 & 20 & 94 & 20 & 0.58 & & \\
\hline $\mathrm{VO}_{2}\left(\%\right.$ pre$\left.-\mathrm{VO}_{2 \max }\right)$ & 53 & 4 & 51 & 3 & 53 & 4 & 51 & 5 & 0.81 & 0.27 & 0.63 \\
\hline Energy expenditure $(\mathrm{kJ} / \mathrm{min})$ & 31.37 & 3.62 & 29.73 & 3.37 & 32.58 & 4.37 & 31.53 & 4.25 & 0.55 & 0.19 & 0.60 \\
\hline RER & 0.94 & 0.03 & 0.91 & 0.02 & 0.91 & 0.04 & 0.91 & 0.04 & 0.12 & 0.66 & 0.17 \\
\hline Fat oxidation (mg/kg per $\mathrm{min}$ ) & $2 \cdot 20$ & 1.09 & $3 \cdot 13$ & 0.74 & 3.03 & $1 \cdot 16$ & $3 \cdot 15$ & $1 \cdot 20$ & 0.13 & 0.80 & 0.21 \\
\hline $\mathrm{CHO}$ oxidation ( $\mathrm{mg} / \mathrm{kg}$ per $\mathrm{min})$ & 22.5 & $4 \cdot 1$ & $18 \cdot 6$ & $3 \cdot 2$ & $19 \cdot 9$ & 6.5 & $18 \cdot 8$ & 6.5 & 0.30 & 0.37 & $0 \cdot 10$ \\
\hline Heart rate (beats per min) & 150 & 15 & 132 & 12 & 138 & 16 & 131 & 14 & 0.10 & 0.04 & 0.01 \\
\hline Borg scale rating $(0-10)$ & 5 & 2 & 3 & 1 & 5 & 1 & 3 & 1 & 0.56 & 0.01 & 0.82 \\
\hline Glucagon $(\mathrm{pg} / \mathrm{ml})$ & $92 \cdot 6$ & 43.1 & 83.1 & $34 \cdot 8$ & 87.6 & $48 \cdot 3$ & 71.9 & $28 \cdot 8$ & 0.81 & 0.07 & 0.60 \\
\hline Insulin $(\mu \mathrm{U} / \mathrm{ml})$ & $5 \cdot 1$ & 1.4 & $5 \cdot 2$ & $1 \cdot 7$ & 5.8 & $3 \cdot 1$ & $5 \cdot 6$ & 1.9 & 0.54 & 0.80 & 0.74 \\
\hline Glucose $(\mathrm{mmol} / \mathrm{l})$ & 4.4 & 0.6 & 4.4 & 0.7 & 4.4 & 0.6 & 4.4 & 0.5 & 0.88 & 0.78 & 0.57 \\
\hline Lactate $(\mathrm{mmol} / \mathrm{l})$ & $2 \cdot 8$ & 0.8 & 1.6 & 0.3 & 2.6 & 1.2 & $2 \cdot 0$ & 0.7 & 0.60 & 0.02 & 0.12 \\
\hline TAG $(\mathrm{mmol} / \mathrm{l})$ & $1 \cdot 18$ & 0.51 & 0.95 & 0.35 & 1.27 & 0.50 & 1.23 & 0.54 & 0.70 & 0.73 & 0.21 \\
\hline $\mathrm{NEFA}(\mathrm{mmol} / \mathrm{l})$ & 0.574 & 0.134 & 0.648 & 0.167 & 0.594 & 0.207 & 0.579 & 0.150 & 0.82 & 0.84 & 0.38 \\
\hline$\beta-\mathrm{HBA}(\mathrm{mmol} / \mathrm{l})$ & 0.051 & 0.026 & 0.085 & 0.058 & 0.055 & 0.055 & 0.047 & 0.031 & 0.86 & 0.71 & 0.16 \\
\hline
\end{tabular}

UFA, unsaturated fatty acids group; $\mathrm{CON}$, control group; $\mathrm{CHO}$, carbohydrate; $\beta$-HBA, $\beta$-hydroxybutyric acid.

acids are ligands for PPAR and exert part of their metabolic effects through this mechanism ${ }^{(6)}$.

\section{Performance}

Time to exhaustion more than doubled after training in both groups, indicating that our training protocol was efficient in increasing exercise capacity. A training-induced attenuation of lactate was observed during the preceding exercise at $50 \% \mathrm{VO}_{2 \max }$, suggesting that at least some of the increase in time to exhaustion may be explained by metabolic adaptations. The effect of training on time to exhaustion was, however, not altered by $n-3$ and $n-9$ fatty acids. It has been shown by Jeukendrup et al. ${ }^{(28)}$ that day-to-day variability is greater in time to exhaustion compared with time trial tests in trained athletes. Therefore time trial tests appear to be more powerful in detecting small effects of treatment on physical performance. However, time trial tests are not suitable for the assessment of endurance capacity of subjects unaccustomed to cycling and endurance competition. Moreover, it has been recently reported that time-to-exhaustion tests allow for assessing changes in performance due to different arterial oxygenation with similar sensitivity as compared with time trial tests ${ }^{(29)}$. Nonetheless, small synergistic effects of unsaturated fatty acids and training on performance might have remained undetected.

In contrast with the improved time to exhaustion, training failed to alter $\mathrm{VO}_{2 \max }$ to any significant extent. This is best explained by the fact that our training protocol included relatively mild exercise duration and intensities over a short period, compared with other training interventions of similar duration that resulted in an increase in $\mathrm{VO}_{2 \max }(30-33)$.

In the present study $\mathrm{HR}$ during exercise at $50 \% \mathrm{VO}_{2 \max }$ was significantly decreased after training. This decrease was significantly greater in UFA. This is consistent with recent reports ${ }^{(34,35)}$, showing that fish oil supplementation lowered HR during submaximal exercise in athletes, but did not further improve endurance capacity compared with controls.
Moreover, the present results are in line with a meta-analysis by Mozaffarian et al. ${ }^{(36)}$ reporting a moderate but significant lowering of resting HR after fish-oil supplementation.

Based on these observations, we conclude that a diet enriched with $n-3$ and $n-9$ fatty acids did not potentiate the effects of training on the performance of previously sedentary young men. This is in accordance with studies performed on well-trained athletes receiving $n-3$ fatty acids, showing no further increase in $\mathrm{VO}_{2 \max }$ compared with controls ${ }^{(34,37,38)}$.
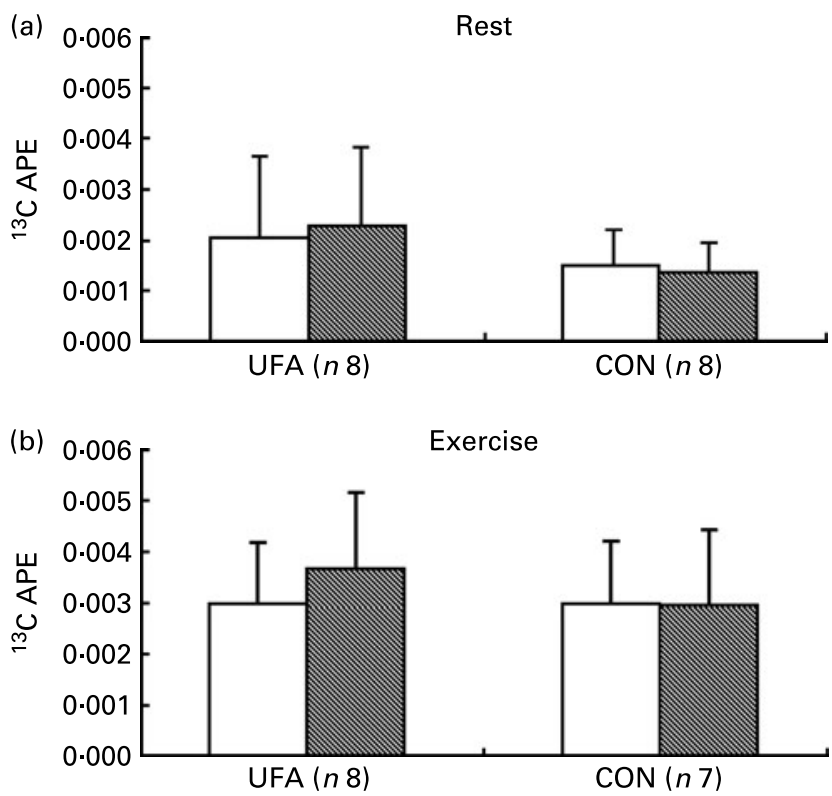

Fig. 3. Qualitative assessment of exogenous oleate oxidation: pre-training $(\square)$; post-training (\$). Values are means, with standard deviations represented by vertical bars. ${ }^{13} \mathrm{C}$ atom percent excess (APE) was assessed at rest (a) $(P=0.35$ for group, $P=0.74$ for time and $P=0.51$ for group $\times$ time $)$ and during exercise (b) at approximately $50 \% \mathrm{VO}_{2 \max }(P=0.99$ for group, $P=0.98$ for time and $P=0.36$ for group $\times$ time) after ingestion of labelled $\left[{ }^{13} \mathrm{C}_{3}\right]$ triolein-olive oil mixture in the unsaturated fatty acids group (UFA) and control group (CON). 


\section{Fat oxidation}

In a recent study performed in our laboratory, Bortolotti et al. ${ }^{(24)}$ reported that fish oil supplementation did not alter net fat oxidation during a single exercise bout. It remained, however, possible that a supplementation with $n-3$ and $n-9$ fatty acids would synergise the effects of endurance training on fat oxidation. In the present study net fat oxidation was assessed by indirect calorimetry at rest, after an overnight fast, during $4 \mathrm{~h}$ after the ingestion of a mixed meal and during exercise at $50 \% \mathrm{VO}_{2 \max }$. We also assessed fat oxidation at rest and during exercise by monitoring breath ${ }^{13} \mathrm{CO}_{2}$ after ingestion of ${ }^{13} \mathrm{C}$-labelled triolein. Fat oxidation was not significantly altered after training in any of the conditions. This result is at odds with a report by Calles-Escandon et al. ${ }^{(39)}$ showing an increased resting fat oxidation after a $10 \mathrm{~d}$ endurance training intervention. The cumulated energy expenditure during the training protocol used in their study was, however, considerably higher than in the present study. The limited total training duration $(5 \mathrm{~h})$ may therefore be a reason why our training protocol did not increase fat oxidation.

\section{Insulin sensitivity}

While the beneficial effects of regular and short-term training on insulin sensitivity are well documented in healthy and insulin-resistant subjects ${ }^{(14,31,40,41)}$, the effects of unsaturated fatty acids, and more specifically of $n-3$ fatty acids, remain more controversial. In healthy subjects, fish oil supplementation did not alter the glycaemic excursion, but lowered the insulin response after a glucose load ${ }^{(42)}$. Several observations suggest that fish oil may improve insulin's actions in insulinresistant human subjects ${ }^{(43)}$ or prevent diet-induced insulin resistance in rodents ${ }^{(6)}$. Other reports, however, indicate that fish oil may also impair insulin secretion, increase glucose production and worsen glucose tolerance in patients with type 2 diabetes ${ }^{(7,9,10)}$.

In the present study insulin decreased a after the ingestion of the test meal in UFA and $\mathrm{CON}$, while glucose concentrations and incAUC remained unchanged. This clearly indicates increased insulin sensitivity, but this effect was, however, not related to changes in fat oxidation. Based on the well-known effects of training on insulin sensitivity it is reasonable to speculate that this effect directly resulted from our training protocol. However, the post-training (but not the pre-training) test was done only $1 \mathrm{~d}$ after the last exercise. Since glucose metabolism can be altered up to $48 \mathrm{~h}$ after an acute bout of exercise ${ }^{(44)}$, it is possible that the last training session contributed to this improved insulin sensitivity. The improvement in insulin sensitivity was similar in subjects having received the diet enriched in $n-3$ and $n-9$ fatty acids $(-27 \%$ insulin incAUC) and the control diet $(-21 \%$ insulin incAUC), indicating that unsaturated fatty acids failed to potentiate the effects of endurance training on insulin sensitivity. However, we observed a trend for basal insulin concentrations to decrease only in UFA $(P=0.09$ for the group $\times$ time interaction), which may suggest that a synergistic effect of unsaturated fatty acids and training remained undetected due to the low statistical power of the study. Furthermore, the present data, observed in young, insulin-sensitive subjects, do not allow us to discard the hypothesis that fish oil may exert such synergistic effect with exercise training in other groups of subjects.

\section{Limitations}

The present study has several limitations, which have to be acknowledged. First, only a small number of subjects were included, and it is therefore possible that subtle effects of unsaturated fatty acids on lipid oxidation may have passed undetected due to a low statistical power. Power analysis indicated that during exercise a minimal fat oxidation difference of $1.9 \mathrm{mg} / \mathrm{kg}$ per min would have had to be present in order to reach statistical significance with a power of 0.8 , and this limit may obviously have been improved, but with a much larger number of subjects. Second, the present study included healthy, insulin-sensitive male subjects, and it remains possible that the combined effects of unsaturated fats and training would be more important in insulin-resistant patients with significant lipotoxicity. Third, an inherent limitation of the present study is the fact that the diets of the two groups differed in the amount of PUFA (EPA and DHA) and MUFA (oleate), making it impossible to assign specific effects to either type of fat. It also resulted in a higher total fat content and a lower carbohydrate content in the UFA group. This is, however, unlikely to have affected our conclusion, that unsaturated fatty acids and training had no synergistic effect with regard to fat oxidation. Finally, compliance to the diet was assessed by monitoring the DHA: palmitate ratio in plasma lipids, but not incorporation of these fatty acids in skeletal muscle membranes. The fact that the DHA:palmitate ratio was significantly higher in UFA compared with CON, however, indicates that the diets were adequately consumed. It remains nonetheless possible that a longer exposition would have been required for unsaturated fatty acids to be incorporated into skeletal muscle membranes and to produce muscle metabolic effects. The observation that HR was reduced with UFA, however, suggests that time of administration was sufficient to produce significant effects, at least on the heart.

\section{Conclusion}

The adaptation to exercise training with regard to performance and insulin sensitivity did not differ between a group receiving a diet enriched with $n-3$ and $n-9$ unsaturated fatty acids and the control group consuming a standard diet containing a high proportion of carbohydrates. It is possible that slight additive or synergistic effects on fatty acid oxidative capacities remained undetected due to the low power of the study.

\section{Acknowledgements}

The study was performed at the Department of Physiology, University of Lausanne, Lausanne, Switzerland.

The present study was supported by a grant from the Eidgenössische Sport Kommission (ESK). We thank the staff of the Department of Physiology of Lausanne for their excellent assistance, and all the volunteers for their participation and commitment. 
The authors' contributions were as follows: P. S., L. T. and A. B. designed the study; P. S. and A. B. performed the experiments; P. S., L. T., C. R., V. L. and A. B. analysed the data; A. B. wrote a draft of the manuscript; P. S., L. T., C. R. and V. L. reviewed and edited the manuscript.

None of the authors had a conflict of interest.

\section{References}

1. Bang HO, Dyerberg J \& Sinclair HM (1980) The composition of the Eskimo food in north western Greenland. Am J Clin Nutr 33, 2657-2661.

2. Lombardo YB \& Chicco AG (2006) Effects of dietary polyunsaturated $n-3$ fatty acids on dyslipidemia and insulin resistance in rodents and humans. A review. J Nutr Biochem 17, $1-13$.

3. Charnock JS, McLennan PL \& Abeywardena MY (1992) Dietary modulation of lipid metabolism and mechanical performance of the heart. Mol Cell Biochem 116, 19-25.

4. Pepe S \& McLennan PL (1996) Dietary fish oil confers direct antiarrhythmic properties on the myocardium of rats. $J$ Nutr 126, 34-42.

5. Owen AJ, Peter-Przyborowska BA, Hoy AJ, et al. (2004) Dietary fish oil dose- and time-response effects on cardiac phospholipid fatty acid composition. Lipids 39, 955-961.

6. Neschen S, Morino K, Dong J, et al. (2007) n-3 Fatty acids preserve insulin sensitivity in vivo in a peroxisome proliferator-activated receptor- $\alpha$-dependent manner. Diabetes 56, 1034-1041.

7. Woodman RJ, Mori TA, Burke V, et al. (2002) Effects of purified eicosapentaenoic and docosahexaenoic acids on glycemic control, blood pressure, and serum lipids in type 2 diabetic patients with treated hypertension. Am J Clin Nutr 76, $1007-1015$.

8. Holness MJ, Greenwood GK, Smith ND, et al. (2003) Diabetogenic impact of long-chain omega-3 fatty acids on pancreatic $\beta$-cell function and the regulation of endogenous glucose production. Endocrinology 144, 3958-3968.

9. Puhakainen I, Ahola I \& Yki-Jarvinen H (1995) Dietary supplementation with $n-3$ fatty acids increases gluconeogenesis from glycerol but not hepatic glucose production in patients with non-insulin-dependent diabetes mellitus. Am J Clin Nutr 61, $121-126$

10. Zambon S, Friday KE, Childs MT, et al. (1992) Effect of glyburide and omega 3 fatty acid dietary supplements on glucose and lipid metabolism in patients with non-insulindependent diabetes mellitus. Am J Clin Nutr 56, 447-454.

11. Couet C, Delarue J, Ritz P, et al. (1997) Effect of dietary fish oil on body fat mass and basal fat oxidation in healthy adults. Int J Obes Relat Metab Disord 21, 637-643.

12. Piers LS, Walker KZ, Stoney RM, et al. (2002) The influence of the type of dietary fat on postprandial fat oxidation rates: monounsaturated (olive oil) vs saturated fat (cream). Int J Obes Relat Metab Disord 26, 814-821.

13. Kien CL, Bunn JY \& Ugrasbul F (2005) Increasing dietary palmitic acid decreases fat oxidation and daily energy expenditure. Am J Clin Nutr 82, 320-326.

14. Boule NG, Weisnagel SJ, Lakka TA, et al. (2005) Effects of exercise training on glucose homeostasis: The Heritage Family Study. Diabetes Care 28, 108-114.

15. Tappy L, Binnert C \& Schneiter P (2003) Energy expenditure, physical activity and body-weight control. Proc Nutr Soc 62, $663-666$.

16. Roberts SO (2000) The role of physical activity in the prevention and treatment of childhood obesity. Pediatr Nurs $\mathbf{2 6}$ $33-36,39-41$.
17. Jeukendrup AE (2003) Modulation of carbohydrate and fat utilization by diet, exercise and environment. Biochem Soc Trans 31, 1270-1273.

18. Owen OE (1988) Resting metabolic requirements of men and women. Mayo Clin Proc 63, 503-510.

19. Hawley JA, Tipton KD \& Millard-Stafford ML (2006) Promoting training adaptations through nutritional interventions. J Sports Sci 24, 709-721.

20. McConell GK, Lee-Young RS, Chen ZP, et al. (2005) Shortterm exercise training in humans reduces AMPK signalling during prolonged exercise independent of muscle glycogen. $J$ Physiol 568, 665-676.

21. Venables MC, Achten J \& Jeukendrup AE (2005) Determinants of fat oxidation during exercise in healthy men and women: a cross-sectional study. J Appl Physiol 98, 160-167.

22. Achten J, Gleeson M \& Jeukendrup AE (2002) Determination of the exercise intensity that elicits maximal fat oxidation. Med Sci Sports Exerc 34, 92-97.

23. Livesey G \& Elia M (1988) Estimation of energy expenditure, net carbohydrate utilization, and net fat oxidation and synthesis by indirect calorimetry: evaluation of errors with special reference to the detailed composition of fuels. Am J Clin Nutr 47, 608-628.

24. Bortolotti M, Tappy L \& Schneiter P (2007) Fish oil supplementation does not alter energy efficiency in healthy males. Clin Nutr 26, 225-230.

25. Horowitz JF, Leone TC, Feng W, et al. (2000) Effect of endurance training on lipid metabolism in women: a potential role for PPAR $\alpha$ in the metabolic response to training. Am $J$ Physiol Endocrinol Metab 279, E348-E355.

26. Russell AP, Feilchenfeldt J, Schreiber S, et al. (2003) Endurance training in humans leads to fiber type-specific increases in levels of peroxisome proliferator-activated receptor- $\gamma$ coactivator-1 and peroxisome proliferator-activated receptor- $\alpha$ in skeletal muscle. Diabetes 52, 2874-2881.

27. Tunstall RJ, Mehan KA, Wadley GD, et al. (2002) Exercise training increases lipid metabolism gene expression in human skeletal muscle. Am J Physiol Endocrinol Metab 283, E66-E72.

28. Jeukendrup A, Saris WH, Brouns F, et al. (1996) A new validated endurance performance test. Med Sci Sports Exerc 28, 266-270.

29. Amann M, Hopkins WG \& Marcora SM (2008) Similar sensitivity of time to exhaustion and time-trial time to changes in endurance. Med Sci Sports Exerc 40, 574-578.

30. Mendenhall LA, Swanson SC, Habash DL, et al. (1994) Ten days of exercise training reduces glucose production and utilization during moderate-intensity exercise. Am J Physiol 266, E136-E143.

31. Gulve EA \& Spina RJ (1995) Effect of 7-10 days of cycle ergometer exercise on skeletal muscle GLUT-4 protein content. J Appl Physiol 79, 1562-1566.

32. Jacobs KA, Paul DR, Geor RJ, et al. (2004) Dietary composition influences short-term endurance training-induced adaptations of substrate partitioning during exercise. Int J Sport Nutr Exerc Metab 14, 38-61.

33. Talanian JL, Galloway SD \& Heigenhauser GJ (2006) Two weeks of high-intensity aerobic interval training increases the capacity for fat oxidation during exercise in women. $J$ Appl Physiol (epublication 14 December 2006).

34. Peoples GE, McLennan PL, Howe PR, et al. (2008) Fish oil reduces heart rate and oxygen consumption during exercise. J Cardiovasc Pharmacol 52, 540-547.

35. Buckley JD, Burgess S, Murphy KJ, et al. (2009) DHArich fish oil lowers heart rate during submaximal exercise in elite Australian rules footballers. J Sci Med Sport 12, 503-507. 
36. Mozaffarian D, Geelen A, Brouwer IA, et al. (2005) Effect of fish oil on heart rate in humans: a meta-analysis of randomized controlled trials. Circulation 112, 1945-1952.

37. Oostenbrug GS, Mensink RP, Hardeman MR, et al. (1997) Exercise performance, red blood cell deformability, and lipid peroxidation: effects of fish oil and vitamin E. J Appl Physiol 83, 746-752.

38. Raastad T, Hostmark AT \& Stromme SB (1997) Omega-3 fatty acid supplementation does not improve maximal aerobic power, anaerobic threshold and running performance in well-trained soccer players. Scand J Med Sci Sports 7, 25-31.

39. Calles-Escandon J, Goran MI, O'Connell M, et al. (1996) Exercise increases fat oxidation at rest unrelated to changes in energy balance or lipolysis. Am $J$ Physiol 270, E1009-E1014.

40. Youngren JF, Keen S, Kulp JL, et al. (2001) Enhanced muscle insulin receptor autophosphorylation with short-term aerobic exercise training. Am $J$ Physiol Endocrinol Metab 280, E528-E533.

41. Winnick JJ, Sherman WM, Habash DL, et al. (2008) Short-term aerobic exercise training in obese humans with type 2 diabetes mellitus improves whole-body insulin sensitivity through gains in peripheral, not hepatic insulin sensitivity. J Clin Endocrinol Metab 93, 771-778.

42. Delarue J, Couet C, Cohen R, et al. (1996) Effects of fish oil on metabolic responses to oral fructose and glucose loads in healthy humans. Am J Physiol 270, E353-E362.

43. Popp-Snijders C, Schouten JA, Heine RJ, et al. (1987) Dietary supplementation of omega-3 polyunsaturated fatty acids improves insulin sensitivity in non-insulin-dependent diabetes. Diabetes Res 4, 141-147.

44. Mikines KJ, Sonne B, Farrell PA, et al. (1988) Effect of physical exercise on sensitivity and responsiveness to insulin in humans. Am J Physiol 254, E248-E259. 